\title{
Association of Diabetes and Admission Blood Glucose Levels with Short-Term Outcomes in Patients with Critical Illnesses
}

This article was published in the following Dove Press journal: Journal of Inflammation Research

\section{Shan Lin (iD) \\ Wanmei He \\ Mian Zeng}

Department of Medical Intensive Care Unit, The First Affiliated Hospital, Sun Yat-sen University, Guangzhou, Guangdong, People's Republic of China
Background: Association of diabetes and admission glucose on the short-term prognosis in patients with critical illnesses are currently ambiguous. We aimed to determine whether diabetes and admission glucose affects short-term prognosis of critically ill patients.

Methods: We performed a retrospective analysis of data on 46,476 critically ill patients from the critical care database. Association of diabetes with 28-day mortality was assessed by inverse probability weighting based on the propensity score. Smoothing splines and threshold effect analysis were applied to explore the relationship between admission glucose and clinical outcomes.

Results: Of the 33,680 patients enrolled in the study, 8,701 (25.83\%) had diabetes. In the main analysis, the 28 -day mortality was reduced by $29 \%$ (hazard ratio $(\mathrm{HR})=0.71,95 \%$ confidence interval (CI) $0.67-0.76$ ) in patients with diabetes compared to those without diabetes. The E-value of 2.17 indicated robustness to unmeasured confounders. Significant interactions were observed for glucose at ICU admission, admission type, and insulin use (Interaction $P<0.05$ ). A V-shaped relationship was observed between admission glucose and 28-day mortality in non-diabetic patients, with the lowest 28-day mortality corresponding to a glucose level of $101.75 \mathrm{mg} / \mathrm{dl}$ (95\% CI 94.64-105.80 mg/dl), and admission hypoglycemia or hyperglycemia should be avoided, especially in patients admitted to the surgical intensive care unit (SICU), cardiac surgery recovery unit (CSRU), and coronary care unit (CCU); for diabetic patients, elevated admission glucose does not appear to be associated with a poor prognosis and perhaps may be beneficial except for CCU and CSRU.

Conclusion: The non-detrimental effect of diabetes on the short-term prognosis of critically ill patients was further confirmed, which would reduce 28-day mortality by approximately $29 \%$. For non-diabetic patients, the admission glucose level corresponding to the lowest 28 day mortality was $101.75 \mathrm{mg} / \mathrm{dl}(95 \%$ CI $94.64-105.80 \mathrm{mg} / \mathrm{dl})$; however, for diabetics, the appropriate admission glucose threshold remains unresolved.

Keywords: critical care, diabetes, glucose, prognosis

\section{Background}

Diabetes is rapidly emerging as a pandemic worldwide. Of the overall US population, approximately 34.2 million people had developed diabetes in 2018, of which 34.1 million were adults ( $>18$ years), accounting for $13.0 \%$ of all US adults. ${ }^{1}$ In critical ill patients admitted to the intensive care units (ICUs), diabetes is a relatively frequent diagnosis. Diabetes occasionally leads to ICU admissions but is usually a part of a comorbid condition. As diabetes is a multifaceted disease that
Department of Medical Intensive Care Unit, The First Affiliated Hospital, Sun Yat-sen University, No. 58 Zhongshan Road 2, Guangzhou, Guangdong 510080, People's Republic of China

Email zengmian@mail.sysu.edu.cn 
can lead to immune system impairments and metabolic dysregulations, treatment of patients is complicated, potentially increasing the severity of the primary disease. ${ }^{2,3}$ On reviewing studies over the past 20 years, the percentage of critically ill patients with diabetes as a comorbid condition was found to range from $13.2 \%$ to $30.4 \% .^{4-14}$ Furthermore, these studies were inconclusive about the relationship between diabetes and the prognosis in patients with acute illness. Some studies suggested that in critically ill patients, diabetes increased the risk of mortality as well as the incidence of infection. ${ }^{8-10}$ Other studies suggested that diabetes may not negatively affect the clinical outcomes of critically ill patients and may even be protective, which seems to conflict with clinical judgment. ${ }^{11-13}$

In addition, there is no consensus on the scope of optimal glycemic control to date. In the past two decades, numerous clinical trials have attempted to explore the optimal range of glycemic control to reduce mortality in critically ill patients; however, these clinical trials have yielded conflicting results. ${ }^{4-7,14-19}$ From the first clinical trial in 2001 until now, there has only been a consensus that the safest range for glycemic control in critically ill patients should not be higher than $180 \mathrm{mg} / \mathrm{dl}$; however, the safest range for glycemic control is still unknown. ${ }^{4}$ Determining the optimal range of glycemic control from the results of clinical trials with large sample sizes is difficult, and previous clinical trials have been both hardwon and praiseworthy. Considering the susceptibility to variations in blood glucose levels in critically ill patients after ICU admission, we examined whether there is a relationship between admission glucose and short-term prognosis in critically ill patients and, if so, to what extent.

The objective of our study was to determine whether diabetes and admission glucose affect short-term prognosis of critically ill patients.

\section{Methods}

\section{Patient Data}

We carried out a retrospective analysis of data on 46,476 critically ill patients from the Critical Care Multiparameter Database III (MIMIC-III) version 1.4. ${ }^{20}$ The Beth Israel Deaconess Medical Center and the institutional review boards of MIT-affiliated institutions granted permission to access the database (Record ID: 33460949). The requirement for patient consent was waived because of the anonymity of data.
All adult ( $\geq 18$ years) patients were recruited for the study, but patients with a follow-up of $>1$ day were included in the analysis. We only analyzed patients who were admitted to the ICU for the first time. Blood glucose was determined on the basis of the first plasma glucose obtained in the patients admitted to the ICUs, which was measured by hospital laboratory staff and uploaded onto the electronic medical records system. Together with conventional variables such as demographic characteristics (age, sex, admission type, etc.), therapeutic interventions, and clinical outcomes, we simultaneously extracted data on the simplified acute physiology score II (SAPS II), ${ }^{21}$ sepsis, and specified comorbidities. Therapeutic interventions included the requirement for mechanical ventilation (MV) or renal replacement therapy (RRT) on the first day and insulin for the entire ICU period. Data were extracted using structured query language (SQL), the website and code to generate support for MIMIC-III documentation are released publicly. ${ }^{22-24}$

\section{Outcomes}

The primary study endpoint was 28-day mortality in critically ill patients.

\section{Statistical Analysis}

Data were expressed as mean \pm standard deviation or median (interquartile range, IQR) for continuous variables, with comparison of group characteristics using the Kruskal-Wallis test (or Fisher's exact test); categorical variables were expressed as numbers and percentages, which were compared using the Chi-square test. We constructed propensity score methods utilizing the following three propensity score models: covariate-adjusted propensity score, propensity score matching (PSM), and inverse probability weighting based on the propensity score. A logistic regression model was used to compute the propensity score, which consisted of the following baseline covariates: age, sex, sepsis, admission type, use of insulin, type of ICU on admission, SAPS II, MV on the first day, glucose at ICU admission, RRT on the first day, cardiac arrhythmias, congestive heart failure, peripheral vascular disease, hypertension, valvular disease, other neurological diseases, chronic pulmonary disease, acquired immune deficiency syndrome (AIDS), liver disease, renal failure, lymphoma, metastatic cancer, solid tumor, obesity, fluid and electrolyte disorders, drug abuse, alcohol abuse, and depression. ${ }^{25}$ Propensity score matching was performed using a 1:1 matching protocol without replacement 
(greedy-matching algorithm), with a caliper width equal to 0.05 of the standard deviation of the logit of the propensity score. For the inverse-probability-weighted analysis, we used the predicted probability of a propensity score model to obtain stable inverse probability weights. ${ }^{26}$ Standardized differences between covariates that were less than $10.0 \%$ represented a relatively balanced condition. $^{27}$ The adjustment variables in the multivariate analysis model were consistent with those in the propensity score models. The results of the main analysis were used along with inverse probability weighting. We also calculated E-values to explore the potential effect of unmeasured confounders of diabetes and 28-day mortality. ${ }^{28,29}$ The E-value allowed for quantifying the required magnitude of an unmeasured confounding factor that might counteract the observed correlation between diabetes and 28-day mortality. The Kaplan-Meier method (Log rank test) was used to describe survival differences of the PSM patients.

Subsequently, to determine whether there was a U-shaped association between 28-day mortality and blood glucose levels on admission, we performed a smoothing splines using a Cox model to fit the 28-day mortality. Inflection points were measured by the twopiece-wise regression model constructed in the threshold effects analysis, with the differences compared via the loglikelihood ratio test and the $95 \%$ confidence interval (CI) for the inflection point computed using the bootstrap method. ${ }^{30}$ Finally, we performed stratified analyses and interaction tests to explore the concordance of the associations for outcomes within different subgroup variables, which included demographic characteristics (eg, age and sex), therapeutic regimens (eg, use of insulin or not), different glucose concentrations, types of ICUs, sepsis, and SAPS II. EmpowerStats (www.empowerstats.com) and $\mathrm{R}$ (http://www.R-project.org, version 3.4.3) were applied to all data analyses. A $P$ value $<0.05$ was considered statistically significant.

\section{Results}

\section{Characteristics of Patients Before and After Propensity Score Matching}

In this study, 33,680 patients with a mean age of 63.65 years were enrolled, among whom 8,701 had diabetes, accounting for about $25.83 \%$ [Table 1 and Figure 1]. Before propensity score matching, there were several differences in the baseline variables between the groups of patients with and without diabetes. With propensity score matching in a 1:1 ratio, 7,261 patients with diabetes were matched with 7,261 patients without diabetes. The model had a C-statistic of 0.8214 . After matching, all variables had standardized differences less than $10.0 \%$, which suggested that the between-group difference was relatively small [Table 2].

\section{Clinical Outcomes in Unmatched and Propensity Score-Matched Patients}

Before matching, there were no obvious differences in the 28-day mortality, in-hospital mortality, or ICU mortality between the two groups (all $P>0.05$ ) [Table 3]. After matching, patients with diabetes had a significantly lower 28-day, ICU, and in-hospital mortality than did those without diabetes (all $P<0.001$ ). Kaplan-Meier curves indicated that patients with diabetes had a considerably better survival advantage than did matched patients without diabetes (Log rank test: $P<0.0001$ ) [Figure 2].

\section{Associations Between with Diabetes and Clinical Outcomes}

As shown in Table 4, a multivariable model with inverse probability weighting based on the propensity score showed that the 28-day mortality rate was reduced by $29 \%$ (hazard ratio $(\mathrm{HR})=0.71,95 \%$ CI $0 .-$ 67-0.76) in the group with diabetes compared with the group without diabetes. The estimated E-value was 2.17 (upper confidence limit 1.96), which means that if there were no immeasurable confounders associated with diabetes as well as 28-day mortality, with relative risks of $\geq 2.17$ for both, then the results we obtained were robust.

\section{Stratified Analyses and Interaction Tests}

Altogether, the effect of the association between diabetes and 28-day mortality was generally in line for all subgroup variables [Table 5 and Figure 3]. Significant interactions were observed for glucose at ICU admission, admission type, and insulin use (Interaction $P<0.05$ ). Admission glucose levels of $140-200 \mathrm{mg} / \mathrm{dl}$ and $\geq 200 \mathrm{mg} / \mathrm{dl}$ were associated with a remarkable reduction in 28-day mortality in patients with diabetes as compared with those without diabetes $(\mathrm{HR}=0.84,95 \%$ CI $0.74-0.95$ and $\mathrm{HR}=0.49,95 \%$ CI $0.46-0.70$, respectively). Patients with diabetes who were admitted to the ICUs in the emergency and urgent settings also had differential reductions in 28-day 
Table I Characteristics of Unmatched Patients

\begin{tabular}{|c|c|c|c|c|}
\hline Variables & $\begin{array}{l}\text { All Patients } \\
(\mathrm{N}=33,680)\end{array}$ & $\begin{array}{l}\text { Without Diabetes } \\
(\mathrm{N}=\mathbf{2 4 , 9 7 9 )}\end{array}$ & $\begin{array}{l}\text { With diabetes } \\
(\mathrm{N}=8701)\end{array}$ & $\begin{array}{l}\text { Standardized } \\
\text { Difference, \% }\end{array}$ \\
\hline Age (years) & $63.65 \pm 17.40$ & $62.44 \pm 18.28$ & $67.10 \pm 14.02$ & 28.6 \\
\hline $\begin{array}{l}\text { Sex } \\
\qquad \text { Male } \\
\text { Female }\end{array}$ & $\begin{array}{l}19,103(56.72 \%) \\
\mid 4,577(43.28 \%)\end{array}$ & $\begin{array}{l}\mid 4,090(56.4 \mid \%) \\
\mid 0,889(43.59 \%)\end{array}$ & $\begin{array}{l}5013(57.61 \%) \\
3688(42.39 \%)\end{array}$ & 2.4 \\
\hline $\begin{array}{l}\text { Admission type } \\
\text { Emergency } \\
\text { Elective } \\
\text { Urgent }\end{array}$ & $\begin{array}{l}27,691 \text { (82.22\%) } \\
5426 \text { (16.11\%) } \\
563(1.67 \%)\end{array}$ & $\begin{array}{l}20,502(82.08 \%) \\
4079(16.33 \%) \\
398(1.59 \%)\end{array}$ & $\begin{array}{l}7189(82.62 \%) \\
1347(15.48 \%) \\
165(1.90 \%)\end{array}$ & 3.3 \\
\hline $\begin{array}{l}\text { Type of ICU on admission } \\
\text { CCU } \\
\text { CSRU } \\
\text { MICU } \\
\text { SICU } \\
\text { TSICU }\end{array}$ & $\begin{array}{l}48||(\mid 4.28 \%) \\
6349(\mid 8.85 \%) \\
|2,07|(35.84 \%) \\
5623(\mid 6.70 \%) \\
4826(\mid 4.33 \%)\end{array}$ & $\begin{array}{l}3344 \text { (13.39\%) } \\
4434 \text { (I7.75\%) } \\
8811 \text { (35.27\%) } \\
4320 \text { (17.29\%) } \\
4070 \text { (I6.29\%) }\end{array}$ & $\begin{array}{l}1467 \text { (16.86\%) } \\
1915(22.01 \%) \\
3260(37.47 \%) \\
1303(14.98 \%) \\
756(8.69 \%)\end{array}$ & 26.3 \\
\hline $\begin{array}{l}\text { Glucose at ICU admission }(\mathrm{mg} / \mathrm{dl}) \\
\text { Sepsis } \\
\text { Use of insulin } \\
\text { SAPS II } \\
\text { MV on the first day } \\
\text { RRT on the first day }\end{array}$ & $\begin{array}{l}\text { I37.20 } 40.96 \\
\mid 1,265(33.45 \%) \\
19,06 \mid(56.59 \%) \\
33.00(24.00-42.00) \\
15,262(45.31 \%) \\
922(2.74 \%)\end{array}$ & $\begin{array}{l}128.39 \pm 32.52 \\
8037(32.18 \%) \\
12,092(48.41 \%) \\
32.00(23.00-41.00) \\
11,260(45.08 \%) \\
513(2.05 \%)\end{array}$ & $\begin{array}{l}162.15 \pm 50.92 \\
3228(37.10 \%) \\
6969(80.09 \%) \\
35.00(27.00-44.00) \\
4002(45.99 \%) \\
409(4.70 \%)\end{array}$ & $\begin{array}{l}79.0 \\
10.4 \\
70.1 \\
22.5 \\
1.8 \\
14.7\end{array}$ \\
\hline $\begin{array}{l}\text { Other comorbidities } \\
\text { Congestive heart failure } \\
\text { Cardiac arrhythmias } \\
\text { Valvular disease } \\
\text { Peripheral vascular disease } \\
\text { Hypertension } \\
\text { Other neurological disease } \\
\text { Chronic pulmonary disease } \\
\text { Liver disease } \\
\text { Renal failure } \\
\text { AIDS } \\
\text { Lymphoma } \\
\text { Metastatic cancer } \\
\text { Solid tumor } \\
\text { Obesity } \\
\text { Fluid and electrolyte disorders } \\
\text { Alcohol abuse } \\
\text { Drug abuse } \\
\text { Depression }\end{array}$ & $\begin{array}{l}814 \mid(24.17 \%) \\
9785(29.05 \%) \\
5267(15.64 \%) \\
3478(10.33 \%) \\
18,544(55.06 \%) \\
4124(12.24 \%) \\
6251(18.56 \%) \\
2407(7.15 \%) \\
4254(12.63 \%) \\
303(0.90 \%) \\
583(1.73 \%) \\
2137(6.35 \%) \\
1717(5.10 \%) \\
1865(5.54 \%) \\
9573(28.42 \%) \\
2812(8.35 \%) \\
1217(3.61 \%) \\
2878(8.55 \%)\end{array}$ & $\begin{array}{l}5192(20.79 \%) \\
6910(27.66 \%) \\
3882(15.54 \%) \\
2307(9.24 \%) \\
12,153(48.65 \%) \\
3246(12.99 \%) \\
4499(18.01 \%) \\
1709(6.84 \%) \\
2225(8.91 \%) \\
263(1.05 \%) \\
465(1.86 \%) \\
1764(7.06 \%) \\
1294(5.18 \%) \\
902(3.61 \%) \\
6820(27.30 \%) \\
2418(9.68 \%) \\
1069(4.28 \%) \\
2124(8.50 \%)\end{array}$ & $\begin{array}{l}2949(33.89 \%) \\
2875(33.04 \%) \\
\text { I } 385(15.92 \%) \\
\text { II I (I3.46\%) } \\
639 \mid(73.45 \%) \\
878(10.09 \%) \\
1752(20.14 \%) \\
698(8.02 \%) \\
2029(23.32 \%) \\
40(0.46 \%) \\
118(1.36 \%) \\
373(4.29 \%) \\
423(4.86 \%) \\
963(11.07 \%) \\
2753(31.64 \%) \\
394(4.53 \%) \\
\mid 48(1.70 \%) \\
754(8.67 \%)\end{array}$ & $\begin{array}{l}29.7 \\
11.7 \\
1.0 \\
13.3 \\
52.6 \\
9.1 \\
5.4 \\
4.5 \\
40.0 \\
6.9 \\
4.0 \\
12.0 \\
1.5 \\
28.9 \\
9.5 \\
20.2 \\
15.2 \\
0.6\end{array}$ \\
\hline
\end{tabular}

Abbreviations: ICU, intensive care unit; SAPS II, simplified acute physiology score II; AIDS, acquired immune deficiency syndrome; CCU, coronary care unit; CSRU, cardiac surgery recovery unit; MICU, medical intensive care unit; SICU, surgical intensive care unit; TSICU, trauma/surgical intensive care unit; MV, mechanical ventilation; RRT, renal replacement therapy.

mortality $(\mathrm{HR}=0.85,95 \%$ CI $0.78-0.93$ and $\mathrm{HR}=0.34$, 95\% CI 0.15-0.77, respectively); however, no significant reduction in 28-day mortality was observed among patients admitted elective. A significant reduction in $28-$ day mortality was observed in diabetic patients with insulin $(\mathrm{HR}=0.76,95 \%$ CI $0.68-0.84)$, whereas the beneficial effect was not observed in diabetic patients without insulin (HR=1.09, 95\% CI 0.93-1.27). 


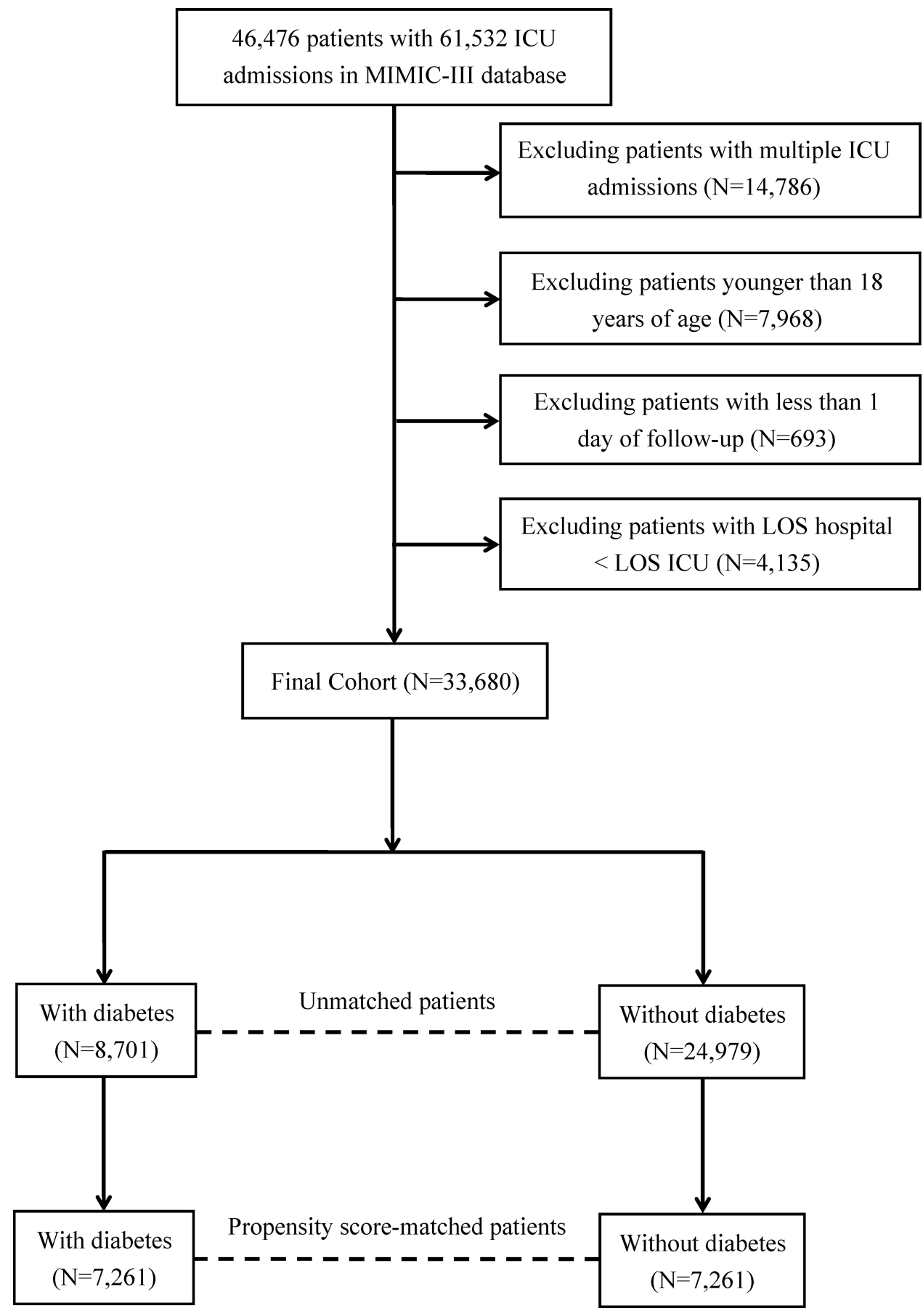

Figure I Flowchart of study participants.

Abbreviations: ICU, intensive care unit; LOS, length of stay.

\section{Smoothing Splines and Threshold Effect Analysis}

We performed smoothing splines of admission blood glucose concentrations to 28-day mortality in patients with and without diabetes, indicating a V-shaped relationship between admission blood glucose and 28-day mortality in patients without diabetes, with either a relatively low or high blood glucose concentration being negatively detrimental to clinical outcomes; however, the effects of admission glucose concentrations on 28-day mortality were intuitively more moderate in diabetics than in non-diabetics [Figure 4]. Subsequently, in the quantitative analysis of the threshold effect, the inflection point 
Table 2 Characteristics of Propensity Score-Matched Patients

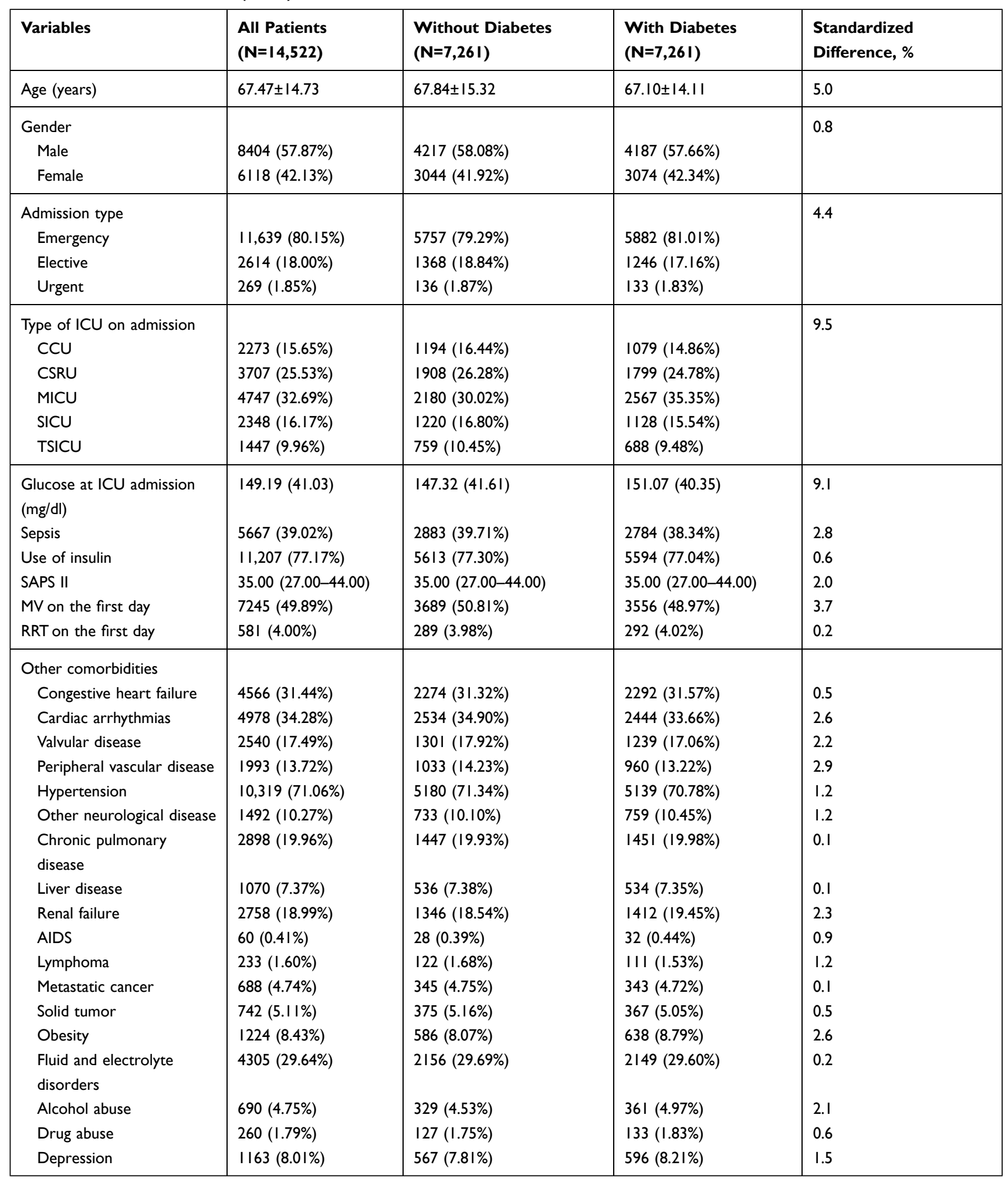

Abbreviations: ICU, intensive care unit; SAPS II, simplified acute physiology score II; AIDS, acquired immune deficiency syndrome; CCU, coronary care unit; CSRU, cardiac surgery recovery unit; MICU, medical intensive care unit; SICU, surgical intensive care unit; TSICU, trauma/surgical intensive care unit; MV, mechanical ventilation; RRT, renal replacement therapy.

was determined to be $101.75 \mathrm{mg} / \mathrm{dl} \quad(95 \%$ CI threshold effect of admission glucose on 28-day mortality $94.64-105.80 \mathrm{mg} / \mathrm{dl}$ ) for 28-day mortality in patients without was markedly significant, namely, the HR for admission gludiabetes. After correction for potential confounders, the cose $<101.75$ was 0.98 , and the HR for admission glucose 
Table 3 Clinical Outcomes in Unmatched and Propensity Score-Matched Patients

\begin{tabular}{|c|c|c|c|c|c|c|}
\hline \multirow[t]{2}{*}{ Clinical Outcomes } & \multicolumn{3}{|c|}{ Unmatched Patients } & \multicolumn{3}{|c|}{ Propensity Score-Matched Patients } \\
\hline & $\begin{array}{l}\text { Without } \\
\text { Diabetes } \\
(\mathbf{N}=\mathbf{2 4 , 9 7 9 )}\end{array}$ & $\begin{array}{l}\text { With } \\
\text { Diabetes } \\
(\mathrm{N}=870 \mathrm{I})\end{array}$ & $P$-value & $\begin{array}{l}\text { Without } \\
\text { Diabetes } \\
(\mathrm{N}=7,26 \mathrm{I})\end{array}$ & $\begin{array}{l}\text { With } \\
\text { Diabetes } \\
(\mathrm{N}=7,26 \mathrm{I})\end{array}$ & $P$-value \\
\hline 28-day mortality, n(\%) & $2715(10.87 \%)$ & 957 (II.00\%) & 0.738 & $964(13.28 \%)$ & 798 (10.99\%) & $<0.001$ \\
\hline ICU mortality, n(\%) & 1502 (6.01\%) & $493(5.67 \%)$ & 0.238 & $588(8.10 \%)$ & $403(5.55 \%)$ & $<0.001$ \\
\hline Hospital mortality, n(\%) & $2300(9.21 \%)$ & 769 (8.84\%) & 0.302 & $855(11.78 \%)$ & $626(8.62 \%)$ & $<0.001$ \\
\hline
\end{tabular}

Abbreviation: ICU, intensive care unit.

$\geq 101.75$ was 1.01 ( $P$-value for log-likelihood ratio test, $<0.001$ ) [Table 6]. As for the 28-day mortality in patients with diabetes, threshold effects analysis revealed that no significant differences were observed in either the one-line linear regression model or the two-piece-wise linear regression model ( $P$-value for log-likelihood ratio test, 0.132) [Table 6]. Additionally, we fitted smoothing splines for the relationship between admission glucose and 28-day mortality in diabetic and non-diabetic patients in different ICUs and further analyzed the effects of different admission glucose level groups

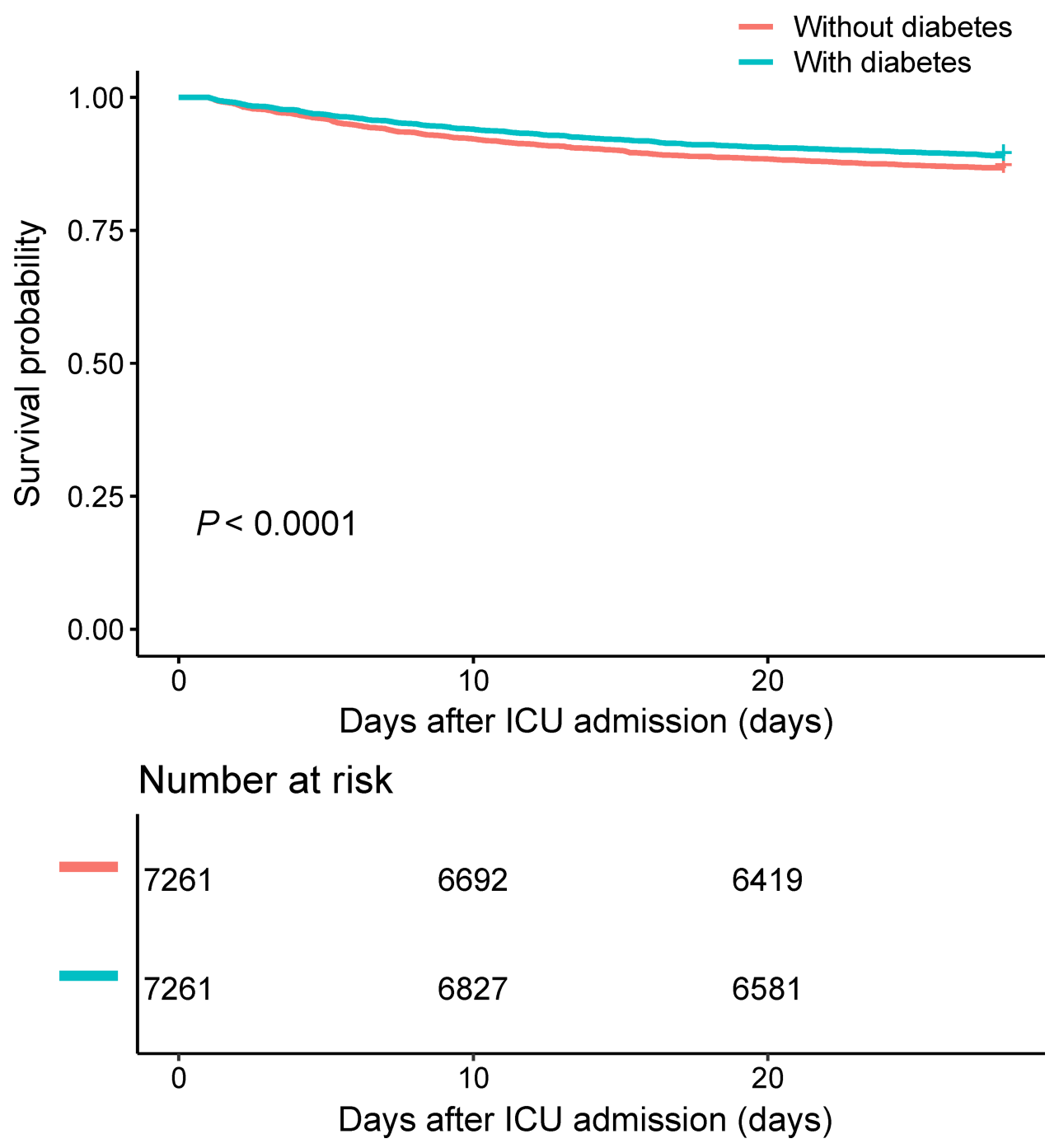

Figure 2 Kaplan-Meier survival curve of the PSM patients.

Abbreviations: ICU, intensive care unit; PSM, propensity score matching. 
Table 4 Associations Between Diabetes and Clinical Outcomes in the Crude Analysis, Multivariable Cox Analysis, and Propensity Score Analyses

\begin{tabular}{|c|c|c|c|}
\hline \multicolumn{4}{|l|}{ Clinical Outcomes } \\
\hline 28-Day Mortality & Groups & HR (95\% Cl) & $P$-value \\
\hline Crude analysis & $\begin{array}{l}\text { Without diabetes } \\
\text { With diabetes }\end{array}$ & $\begin{array}{l}\text { Ref. } \\
\text { I.0I (0.94-1.09) }\end{array}$ & $\begin{array}{l}- \\
0.8045\end{array}$ \\
\hline Multivariable analysis & $\begin{array}{l}\text { Without diabetes } \\
\text { With diabetes }\end{array}$ & $\begin{array}{l}\text { Ref. } \\
0.86(0.79-0.93)\end{array}$ & 0.0004 \\
\hline \multicolumn{4}{|l|}{ Propensity-score models } \\
\hline $\begin{array}{l}\text { Adjusted for } \\
\text { propensity score }\end{array}$ & $\begin{array}{l}\text { Without diabetes } \\
\text { With diabetes }\end{array}$ & $\begin{array}{l}\text { Ref. } \\
0.90(0.83-0.98)\end{array}$ & $\begin{array}{l}- \\
0.0132\end{array}$ \\
\hline With matching & $\begin{array}{l}\text { Without diabetes } \\
\text { With diabetes }\end{array}$ & $\begin{array}{l}\text { Ref. } \\
0.81(0.74-0.89)\end{array}$ & $\begin{array}{l}- \\
<0.0001\end{array}$ \\
\hline $\begin{array}{l}\text { With inverse } \\
\text { probability weighting }\end{array}$ & $\begin{array}{l}\text { Without diabetes } \\
\text { With diabetes }\end{array}$ & $\begin{array}{l}\text { Ref. } \\
0.7 \mid(0.67-0.76)\end{array}$ & $\begin{array}{l}- \\
<0.0001\end{array}$ \\
\hline
\end{tabular}

Notes: Multivariable analysis adjusted for age, sex, sepsis, admission type, use of insulin, type of ICU on admission, SAPS II, glucose at ICU admission, MV on the first day, RRT on the first day, cardiac arrhythmias, congestive heart failure, peripheral vascular disease, valvular disease, hypertension, other neurological diseases, chronic pulmonary disease, renal failure, liver disease, AIDS, lymphoma, metastatic cancer, solid tumor, obesity, fluid and electrolyte disorders, alcohol abuse, drug abuse, and depression; Propensity score was calculated by age, sex, sepsis, admission type, use of insulin, type of ICU on admission, SAPS II, glucose at ICU admission, MV on the first day, RRT on the first day, cardiac arrhythmias, congestive heart failure, peripheral vascular disease, valvular disease, hypertension, other neurological diseases, chronic pulmonary disease, renal failure, liver disease, AIDS, lymphoma, metastatic cancer, solid tumor, obesity, fluid and electrolyte disorders, alcohol abuse, drug abuse, and depression; Propensity score matching was performed with the use of a I:I matching protocol without replacement (greedymatching algorithm), with a caliper width equal to 0.05 of the standard deviation of the logit of the propensity score; Inverse probability weighting was used with the same covariates according to the propensity score.

Abbreviations: $\mathrm{HR}$, hazard ratio; $\mathrm{Cl}$, confidence interval.

on 28-day mortality in diabetic and non-diabetic patients in different ICUs [Table 7, and Figures 5 and 6]. As shown in Table 7, we found that in non-diabetic patients, admission blood glucose level $>200 \mathrm{mg} / \mathrm{dl}$ had variable adverse effects on different ICU patients, especially those in the cardiac surgery recovery unit (CSRU) $(\mathrm{HR}=3.68,95 \%$ CI 1.57-8.60). Moreover, admission blood glucose level $<70 \mathrm{mg} / \mathrm{dl}$, especially among patients in the surgical intensive care unit (SICU), was associated with a significant increase in 28-day mortality $(\mathrm{HR}=10.17,95 \%$ CI 2.49-41.57). In diabetic patients, admission hyperglycemia $(\geq 200 \mathrm{mg} / \mathrm{dl})$ was equally detrimental to the patients in the coronary care unit (CCU) and those in the CSRU $(\mathrm{HR}=2.35$, 95\% CI $1.44-3.81$ and $\mathrm{HR}=3.53$, 95\% CI 1.37-9.12), whereas in the other ICUs, admission hyperglycemia was not associated with a poor prognosis, and is perhaps beneficial for the patients.

\section{Discussion}

In this study, we purposefully selected a well-represented study population of critically ill patients admitted to ICUs from a large critical healthcare database and investigated the clinical outcomes of these patients with and without diabetes, in addition to exploring the impact of blood glucose at ICU admission on the presence or absence of diabetes. We found that 1) diabetes was not a detrimental factor for critically ill patients in the ICUs, which would reduce the risk of 28-day mortality by about $29 \%, 2$ ) a V-shaped relationship was observed between admission glucose and 28-day mortality in patients without diabetes, and hypoglycemia or hyperglycemia should be avoided, especially in patients admitted to the SICU, CSRU, and CCU; for patients with diabetes, an elevated admission glucose does not appear to be associated with a poor prognosis and is perhaps beneficial for certain ICU patients, and 3) particular attention should be paid to admission hypoglycemic events in critically ill patients without diabetes in the SICU and admission hyperglycemic events in all critically ill patients in the CCU and CSRU regardless of the presence of diabetes, which warrants the attention of clinicians.

Currently, the mechanisms underlying what appears to be a predominantly neutrally or protective link between diabetes and mortality in critically ill patients continue to be elusive. If diabetes is associated with decreased mortality in patients with critical illness, just a single mechanism may not be involved. Biologically, part of the potential mechanism may be that glucose plays a critical role in the function of activated immune cells and that glucose is a key contributor to energy production and maintenance of immune cell functions as well as the synthesis of immunomodulators. ${ }^{31-33}$ Furthermore, diabetic patients develop a tolerance to hyperglycemia because of chronically elevated blood glucose concentrations, making the harmful hyperglycemia transform into an "energy factory", and for the harmful effects to persist, higher blood glucose concentrations would be required. ${ }^{34}$ Namely, the smoothing splines revealed graphically that blood glucose level has a relatively small effect on patients with diabetes, and in subsequent further analyses, elevated blood glucose was not statistically associated with an increase in 28-day mortality. Our results also revealed an association between the use of insulin and diabetes on 28-day mortality, that is, there was a significant reduction in 28-day mortality in patients with diabetes who used insulin, whereas no such 
Table 5 Effect Size of Diabetes on 28-Day Mortality Rate in Prespecified and Exploratory Subgroups in Each Subgroup

\begin{tabular}{|c|c|c|c|c|}
\hline \multirow[t]{2}{*}{$Y=28-D a y$ Mortality } & \multicolumn{4}{|l|}{ Adjusted Model } \\
\hline & Without Diabetes & With Diabetes, HR (95\% Cl) & $P$-value & $P$ for Interaction \\
\hline Age (years) & & & & 0.3461 \\
\hline$<65$ & 1.0 & $0.86(0.72-1.01)$ & 0.0732 & \\
\hline$\geq 65$ & 1.0 & $0.86(0.78-0.95)$ & 0.0021 & \\
\hline Sex & & & & 0.7880 \\
\hline Male & 1.0 & $0.85(0.76-0.96)$ & 0.0067 & \\
\hline Female & 1.0 & $0.87(0.77-0.98)$ & 0.0242 & \\
\hline Glucose at ICU admission (mg/dl) & & & & $<0.0001$ \\
\hline$<140$ & 1.0 & $1.03(0.91-1.17)$ & 0.6588 & \\
\hline$\geq 140,<200$ & 1.0 & $0.84(0.74-0.95)$ & 0.0061 & \\
\hline$\geq 200$ & 1.0 & $0.57(0.46-0.70)$ & $<0.0001$ & \\
\hline Admission type & & & & 0.0280 \\
\hline Emergency & 1.0 & $0.85(0.78-0.93)$ & 0.0003 & \\
\hline Elective & 1.0 & $1.22(0.80-1.84)$ & 0.3529 & \\
\hline Urgent & 1.0 & $0.34(0.15-0.77)$ & 0.0101 & \\
\hline Type of ICU on admission & & & & 0.1173 \\
\hline $\mathrm{CCU}$ & 1.0 & $0.61(0.49-0.76)$ & $<0.0001$ & \\
\hline CSRU & 1.0 & $0.94(0.66-1.33)$ & 0.7151 & \\
\hline MICU & 1.0 & $0.94(0.83-1.06)$ & 0.3221 & \\
\hline SICU & 1.0 & $0.81(0.66-0.98)$ & 0.0315 & \\
\hline TSICU & 1.0 & $0.96(0.74-1.23)$ & 0.7236 & \\
\hline SAPS II & & & & 0.1625 \\
\hline$<30$ & 1.0 & $0.69(0.50-0.94)$ & 0.0202 & \\
\hline$\geq 30,<60$ & 1.0 & $0.79(0.7 \mathrm{I}-0.87)$ & $<0.0001$ & \\
\hline$\geq 60$ & 1.0 & $1.14(0.95-1.38)$ & 0.1613 & \\
\hline Use of insulin & & & & 0.0007 \\
\hline No & 1.0 & $1.09(0.93-1.27)$ & 0.2952 & \\
\hline Yes & 1.0 & $0.76(0.68-0.84)$ & $<0.0001$ & \\
\hline Sepsis & & & & 0.1191 \\
\hline NO & 1.0 & $0.90(0.80-1.01)$ & 0.0655 & \\
\hline YES & 1.0 & $0.82(0.73-0.93)$ & 0.0019 & \\
\hline$M V$ on the first day & & & & 0.6200 \\
\hline NO & 1.0 & $0.84(0.74-0.96)$ & 0.0078 & \\
\hline YES & 1.0 & $0.87(0.78-0.97)$ & 0.0147 & \\
\hline RRT on the first day & & & & 0.7566 \\
\hline NO & 1.0 & $0.86(0.79-0.94)$ & 0.0005 & \\
\hline YES & 1.0 & $0.88(0.63-1.23)$ & 0.4665 & \\
\hline
\end{tabular}

Notes: Adjusted by age, sex, sepsis, admission type, use of insulin, type of ICU on admission, SAPS II, mechanical ventilation on first day, glucose at ICU admission, renal replacement therapy on first day, cardiac arrhythmias, congestive heart failure, peripheral vascular disease, valvular disease, hypertension, other neurological diseases, chronic pulmonary disease, renal failure, liver disease, AIDS, lymphoma, metastatic cancer, solid tumor, obesity, fluid and electrolyte disorders, alcohol abuse, drug abuse, and depression except for the subgroup variable.

Abbreviations: HR, hazard ratio; Cl, confidence interval; ICU, intensive care unit; SAPS II, simplified acute physiology score II; CCU, coronary care unit; CSRU, cardiac surgery recovery unit; MICU, medical intensive care unit; SICU, surgical intensive care unit; TSICU, trauma/surgical intensive care unit; MV, mechanical ventilation; RRT, renal replacement therapy.

difference between patients with and without diabetes who did not use insulin was observed. Further analysis of the with or without insulin used cohort revealed that only
1732 patients $(11.85 \%)$ had diabetes in the non-insulin cohort, which may have weakened the decreasing effect of 28-day mortality in the diabetes cohort and resulted in 


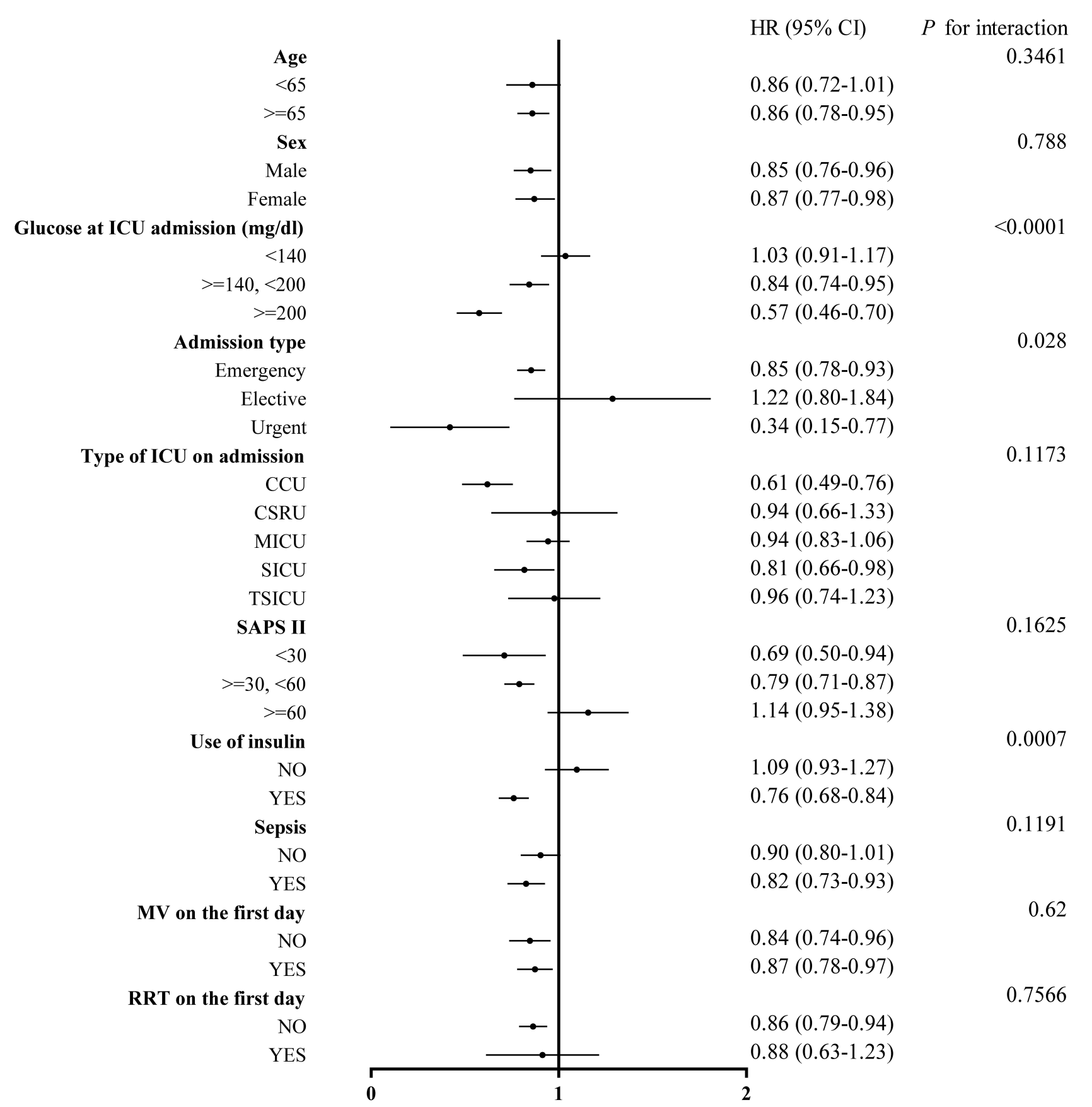

Figure 3 Forest plot of diabetes on 28-day mortality in prespecified and exploratory subgroups in each subgroup.

Abbreviations: ICU, intensive care unit; SAPS II, simplified acute physiology score II; CCU, coronary care unit; CSRU, cardiac surgery recovery unit; MICU, medical intensive care unit; SICU, surgical intensive care unit; TSICU, trauma/surgical intensive care unit; MV, mechanical ventilation; RRT, renal replacement therapy.

the negative findings. However, this does not completely refute the association between diabetes and favorable outcomes, from an HR of 0.86 in multivariable analysis to an HR of 0.76 in stratified analysis, suggesting that the insulin use further reduced 28-day mortality in diabetic patients. The underlying mechanisms have been partially explained in previous studies with dysfunctional autophagy in critically ill patients, which plays a key role in both host defense and cell survival; ${ }^{35,36}$ insulin not only plays a role in glucose regulation but also inhibits the autophagic catabolic process. ${ }^{37}$ Still, the occurrence of hypoglycemia resulting from the use of insulin should not be ignored. Although the incidence of hypoglycemia was high in the two Leuven studies, ${ }^{4,5}$ the condition of patients who experienced hypoglycemia did not worsen when compared to that in who did not experience 


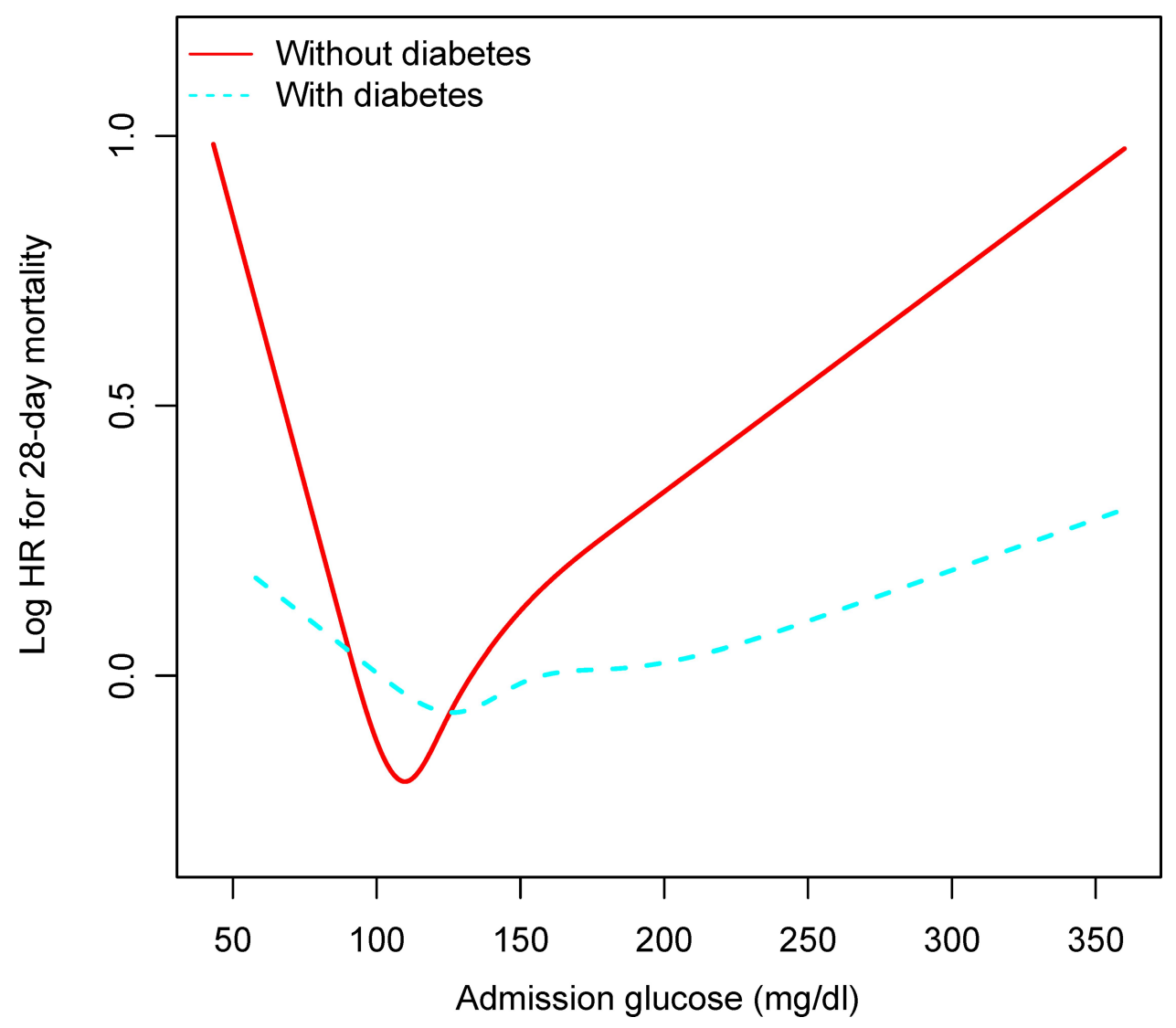

Figure 4 Association between admission glucose and 28-day mortality in critically ill patients with and without diabetes. Abbreviation: HR, hazard ratio.

hypoglycemia. The use of intensive insulin therapy to lower the blood glucose level to normal values requires careful monitoring of blood glucose, as classical neurological symptoms can be offset by sedation or underlying mental status disorders.

In terms of glucose concentrations, glycemic control in critically ill patients is still an area of considerable concern. The initial recognition of the potentially detrimental effects of hyperglycemia prompted a sequence of studies that targeted intensive insulin treatment strategies with the goal of tight glycemic control. With the accumulation of knowledge, however, there have been mixed results regarding interventions for intensive insulin therapy, ie, the excessive pursuit of tight glycemic control in critically ill patients is exactly a counterproductive step. ${ }^{4,14-19}$ On the basis of the data from the two Leuven studies, it was considered practical to achieve blood glucose levels of $80-110 \mathrm{mg} / \mathrm{dl}$ (rather than 180-200 mg/dl). ${ }^{4,5}$ The NICE-SUGAR study concluded that a blood glucose target of $180 \mathrm{mg} / \mathrm{dl}$ or less was less likely to result in mortality than a target of $81-108 \mathrm{mg} / \mathrm{dl} .{ }^{7}$ Krinsley et al adopted different glycemic control strategies on the basis of diabetes status and hemoglobin $\mathrm{A} 1 \mathrm{c}(\mathrm{HbAlc})$ levels in critically ill patients and found that a blood glucose level of $80-140 \mathrm{mg} / \mathrm{dl}$ was safe and effective in patients without diabetes and in those with diabetes but with a low HbAlc level; however, for patients with diabetes and $\mathrm{HbAlc}$ levels greater than $7 \%$, the glycemic target remains ambiguous. ${ }^{19}$ These findings mean that the moderate glycemic control strategy has been widely established in critically ill patients. Currently, an accurate answer regarding optimal blood glucose concentrations remains elusive. Moreover, the complexity and variability of conducting large samples of clinical trials is well known. Our findings were consistent with the "personalized" strategy for patients with and without diabetes. In our study, for patients without diabetes, the admission glucose concentration corresponding to the lowest 28-day mortality was $101.75 \mathrm{mg} /$ dl $(95 \%$ CI $94.64-105.80 \mathrm{mg} / \mathrm{dl})$, whereas for critically ill patients with diabetes, admission hyperglycemia did not significantly increase the 28-day mortality, and they even benefited from a higher blood glucose level (up to $200 \mathrm{mg} / \mathrm{dl}$ ), with the exception of patients admitted to the CCU and CSRU. Our study primarily established an optimal threshold for the 
Table 6 Threshold Effect Analysis of Glucose Levels and 28-Day Mortality Rate Using Piece-Wise Linear Regression

\begin{tabular}{|c|c|c|c|}
\hline \multicolumn{4}{|c|}{ Outcome: 28-day mortality (with diabetes) } \\
\hline \multicolumn{4}{|c|}{$\begin{array}{l}\text { One-line linear regression model: } \mathrm{HR}=1.00 \mathrm{I}, 95 \% \mathrm{Cl}(\mathrm{I} .000-1.002) \text {, } \\
P=0.2 \mathrm{I} 55\end{array}$} \\
\hline \multicolumn{4}{|c|}{ The two-piece-wise linear regression model } \\
\hline Infection point & HR & $95 \% \mathrm{Cl}$ & $P$-value \\
\hline$<258.25 \mathrm{mg} / \mathrm{dl}$ & 1.00 & $1.00-1.00$ & 0.8098 \\
\hline$\geq 258.25 \mathrm{mg} / \mathrm{dl}$ & 1.01 & $1.00-1.01$ & 0.0760 \\
\hline \multicolumn{4}{|c|}{ The log-likelihood ratio test: $P=0.132$} \\
\hline \multicolumn{4}{|c|}{ The confidence interval of the inflection point: $98.75-260.00 \mathrm{mg} / \mathrm{dl}$} \\
\hline \multicolumn{4}{|c|}{ Outcome: 28-day mortality (without diabetes) } \\
\hline \multicolumn{4}{|c|}{$\begin{array}{l}\text { One-line linear regression model: } \mathrm{HR}=1.004,95 \% \mathrm{Cl}(\mathrm{I} .003-1.005) \text {, } \\
P<0.000 \mathrm{I}\end{array}$} \\
\hline \multicolumn{4}{|c|}{ The two-piece-wise linear regression model } \\
\hline Infection point & HR & $95 \% \mathrm{Cl}$ & $P$-value \\
\hline$<101.75 \mathrm{mg} / \mathrm{dl}$ & 0.98 & $0.97-0.99$ & $<0.0001$ \\
\hline$\geq 101.75 \mathrm{mg} / \mathrm{dl}$ & 1.01 & $1.00-1.01$ & $<0.0001$ \\
\hline \multicolumn{4}{|c|}{ The log-likelihood ratio test: $P<0.001$} \\
\hline
\end{tabular}

Notes: Adjusted by age, sex, sepsis, admission type, use of insulin, type of ICU on admission, SAPS II, MV on the first day, RRT on the first day, cardiac arrhythmias, congestive heart failure, peripheral vascular disease, valvular disease, hypertension, other neurological diseases, chronic pulmonary disease, renal failure, liver disease, AIDS, lymphoma, metastatic cancer, solid tumor, obesity, fluid and electrolyte disorders, alcohol abuse, drug abuse, and depression.

Abbreviations: $\mathrm{HR}$, hazard ratio; $\mathrm{Cl}$, confidence interval.

glycemic range by retrospective analysis of a large sample, which may potentially inform the practice of glycemic control and treatment strategies in critically ill patients. Nonetheless, it should be noted that we used blood glucose concentrations at ICU admission, which, although minimizing treatment effects, we acknowledged that this might not be fully extrapolated to the optimal range of glycemic control.

There are limitations of our study as well. First, we attempted to obtain information on the plasma glucose levels at ICU admission to eliminate the influence of interventions on glucose levels, but we were unable to definitively state whether the interventions that the patients received before ICU admission, such as intravenous fluid administration and steroid hormone injection, affected glucose levels. Second, as no data on $\mathrm{HbA} 1 \mathrm{c}$ levels are available yet, we cannot exclude the possibility of new-onset diabetes. Indeed, in previous studies on measuring $\mathrm{HbA} 1 \mathrm{c}$ in patients without diabetes, it was found that $5.5 \%, 6.8 \%$, and $9.3 \%$ of critically ill patients had higher than normal HbAlc levels, ${ }^{38-40}$ confirming that certain patients may have had undetected diabetes before ICU admission. In addition, it should be emphasized that our study did not differentiate the patients' diabetes type (eg, type 1 or type 2). Third, we were unable to obtain information on the duration, severity, and complications of diabetes, as well as medication prescribed and therefore could not measure the impact of these factors on the outcomes. We used different models, including inverse-probability-weighted analysis, to investigate the independent role of diabetes and the clinical outcomes, but as with all retrospective studies, it was possible that residual confounders may exist. However, these clinical and electronic data were prospectively collected and independently measured, which makes them not easily amenable to manipulation. In addition, with the calculation of E-value to quantify the potential impact of unmeasured confounders, we found that unmeasured confounders are not likely to contribute to the overall effect. Fourth, we should be cautious in interpreting these results, as the results of a correlation analysis should not be mistaken for proof of causality. Finally, as the single-center study design results in reduced external validity, the aspects of glycemic control strategies and mortality reduction differing between critically ill patients with and without diabetes warrant prospective studies that can address the aforementioned limitations.

\section{Conclusions}

From this retrospective review of the prospectively collected data, the non-detrimental effect of diabetes on the short-term prognosis of critically ill patients was further confirmed, which would reduce 28-day mortality by approximately $29 \%$. Furthermore, for non-diabetic patients, the admission glucose levels corresponding to the lowest 28-day mortality was $101.75 \mathrm{mg} / \mathrm{dl} \quad(95 \% \quad$ CI 94.64-105.80 $\mathrm{mg} / \mathrm{dl}$ ), and admission hypoglycemic or hyperglycemic events should be avoided as much as possible, especially in patients admitted to the SICU, CSRU, and CCU. Moreover, for diabetic patients other than those admitted in the CCU and CSRU, elevated admission glucose do not appear to be associated with a poor prognosis and could benefit the patients as well. Finally, clinicians should be particularly attentive to admission hypoglycemic events in critically ill patients without diabetes in the SICU and to admission hyperglycemic events in critically ill patients in the CCU and CSRU, regardless of the presence of diabetes. 
Table 7 Effect of Admission Glucose Levels on 28-Day Mortality in Different ICU Patients with and without Diabetes

\begin{tabular}{|c|c|c|c|c|}
\hline Type of ICU & $\geq 70,<140 \mathrm{mg} / \mathrm{dl}$ & $<70 \mathrm{mg} / \mathrm{dl}$ & $\geq 140,<200 \mathrm{mg} / \mathrm{dl}$ & $\geq 200 \mathrm{mg} / \mathrm{dl}$ \\
\hline \multicolumn{5}{|c|}{ Without Diabetes (HR, 95\% Cl, P-value) } \\
\hline $\mathrm{CCU}$ & 1.0 & $2.20(0.30-16.20) 0.4377$ & $1.24(0.98-1.57) 0.0685$ & $2.27(1.58-3.27)<0.0001$ \\
\hline CSRU & 1.0 & 1.0 & $2.56(1.73-3.77)<0.0001$ & $3.68(1.57-8.60) 0.0026$ \\
\hline MICU & 1.0 & $1.35(0.70-2.62) 0.3764$ & $1.05(0.93-1.20) 0.4311$ & $1.43(1.16-1.76) 0.0008$ \\
\hline SICU & 1.0 & $10.17(2.49-41.57) 0.0012$ & $1.33(1.10-1.61) 0.0032$ & $2.28(I .52-3.4 I)<0.000 I$ \\
\hline TSICU & 1.0 & $2.59(0.34-19.43) 0.3559$ & $1.58(1.27-1.98)<0.0001$ & $2.06(1.20-3.55) 0.0091$ \\
\hline Total & 1.0 & $1.57(0.91-2.73) 0.1062$ & $1.25(1.15-1.37)<0.0001$ & $1.80(1.54-2.10)<0.0001$ \\
\hline \multicolumn{5}{|c|}{ With Diabetes (HR, 95\% Cl, P-value) } \\
\hline $\mathrm{CCU}$ & 1.0 & $2.95(0.39-22.5 I) 0.2963$ & $1.72(1.10-2.69) 0.0172$ & 2.35 (I.44-3.8I) 0.0006 \\
\hline CSRU & 1.0 & 1.0 & $1.14(0.62-2.13) 0.6689$ & $3.53(1.37-9.12) 0.0092$ \\
\hline MICU & 1.0 & $0.43(0.10-1.76) 0.2399$ & $0.80(0.65-0.99) 0.0390$ & $0.74(0.58-0.95) 0.0180$ \\
\hline SICU & 1.0 & 0.00 (0.00-Inf) 0.9939 & $0.97(0.66-1.42) 0.8764$ & $1.22(0.77-1.94) 0.3956$ \\
\hline TSICU & 1.0 & 0.00 (0.00-Inf) 0.9980 & I.I4 (0.7I-I.84) 0.5916 & $1.05(0.58-1.90) 0.8626$ \\
\hline Total & 1.0 & $0.60(0.19-1.90) 0.3878$ & I.0I (0.87-I.I8) 0.8775 & $1.09(0.9|-| .3 \mid) 0.3306$ \\
\hline
\end{tabular}

Notes: Adjusted by age, sex, sepsis, admission type, use of insulin, type of ICU on admission, SAPS II, MV on the first day, RRT on the first day, cardiac arrhythmias, congestive heart failure, peripheral vascular disease, valvular disease, hypertension, other neurological diseases, chronic pulmonary disease, renal failure, liver disease, AIDS, lymphoma, metastatic cancer, solid tumor, obesity, fluid and electrolyte disorders, alcohol abuse, drug abuse, and depression.

Abbreviations: HR, hazard ratio; Cl, confidence interval; ICU, intensive care unit; SAPS II, simplified acute physiology score II; CCU, coronary care unit; CSRU, cardiac surgery recovery unit; MICU, medical intensive care unit; SICU, surgical intensive care unit; TSICU, trauma/surgical intensive care unit.

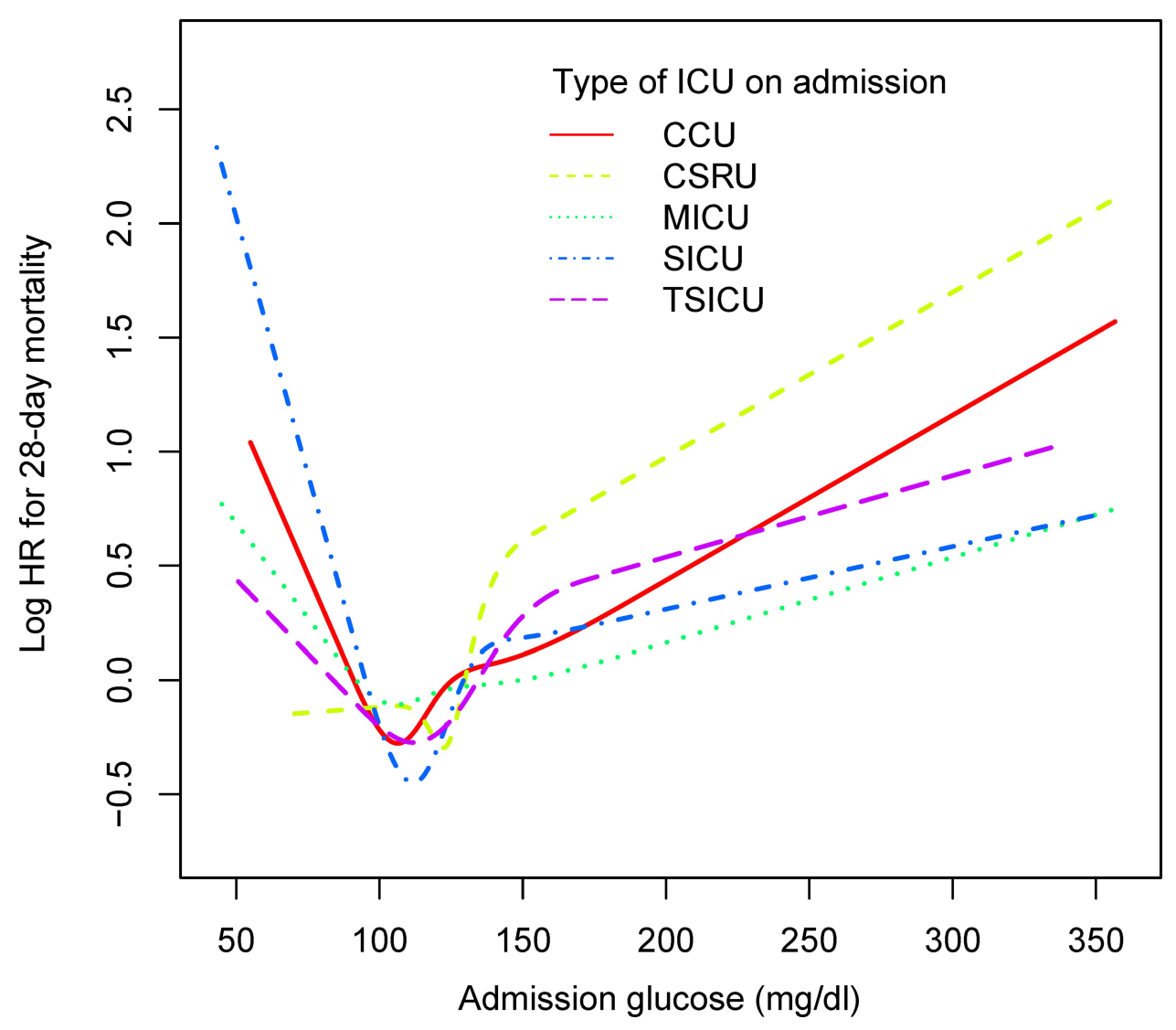

Figure 5 Association between admission glucose and 28-day mortality in critically ill patients without diabetes admitted to different ICU types.

Abbreviations: HR, hazard ratio; ICU, intensive care unit; CCU, coronary care unit; CSRU, cardiac surgery recovery unit; MICU, medical intensive care unit; SICU, surgical intensive care unit; TSICU, trauma/surgical intensive care unit. 


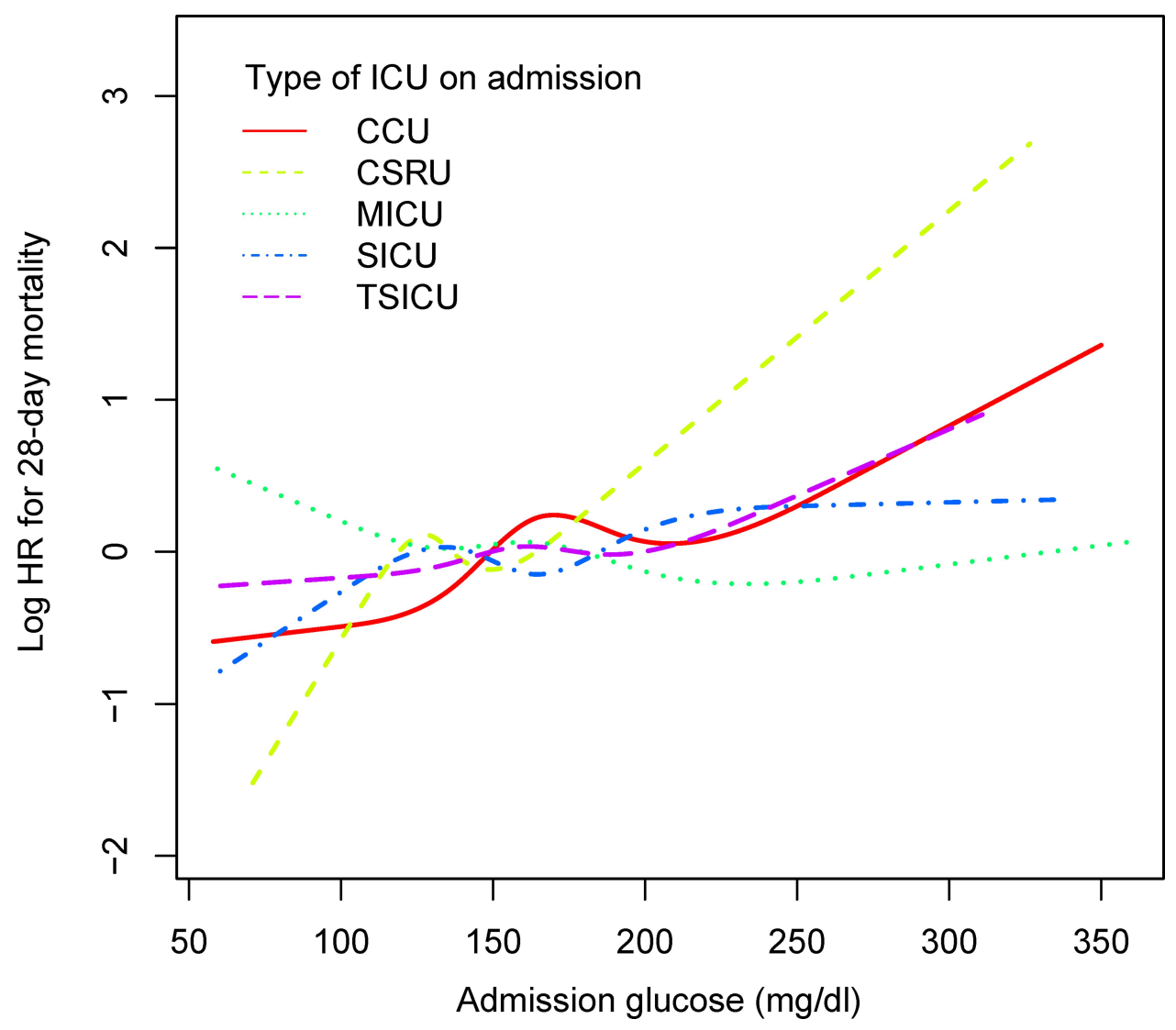

Figure 6 Association between admission glucose and 28-day mortality in critically ill patients with diabetes admitted to different ICU types.

Abbreviations: HR, hazard ratio; ICU, intensive care unit; $\mathrm{CCU}$, coronary care unit; CSRU, cardiac surgery recovery unit; MICU, medical intensive care unit; SICU, surgical intensive care unit; TSICU, trauma/surgical intensive care unit.

\section{Abbreviations}

ICU, intensive care unit; SAPS II, simplified acute physiology score II; AIDS, acquired immune deficiency syndrome; PSM, propensity score matching; SQL, structure query language; IQR, interquartile range; $\mathrm{CI}$, confidence interval; HR, hazard ratio; $\mathrm{CCU}$, coronary care unit; CSRU, cardiac surgery recovery unit; MICU, medical intensive care unit; SICU, surgical intensive care unit; TSICU, trauma/surgical intensive care unit.

\section{Acknowledgments}

Thanks to Ruizhe Wang (Tencent Technology Co., Ltd. Shenzhen, Guangdong, China) for his help in the SQL code.

\section{Funding}

This work was supported by the National Natural Science Foundation of China [Grant number: 81670066]; the Major Science and Technology Planning Project of Guangdong Province, China [Grant number: 2016A020216009]; the Critical Care Research Funding of the Aesculap Academy (2017); the Guangdong Basic and Applied Basic Research Foundation, China [Grant number: 2019A1515011198].

\section{Disclosure}

All authors report no conflicts of interest for this work.

\section{References}

1. Centers for Disease Control and Prevention. National diabetes statistics report, 2020. Atlanta, GA: Centers for Disease Control and Prevention, US Department of Health and Human Services; 2020.

2. Muller L, Gorter KJ, Hak E, et al. Increased risk of common infections in patients with type 1 and type 2 diabetes mellitus. Clin Infect Dis. 2005;41(3):281-288. doi:10.1086/431587

3. Schuetz P, Castro P, Shapiro NI. Diabetes and sepsis: preclinical findings and clinical relevance. Diabetes Care. 2011;34(3):771-778. doi: $10.2337 /$ dc10-1185

4. Van Den Berghe G, Wouters P, Weekers F, et al. Intensive insulin therapy in critically ill patients. $N$ Engl $J$ Med. 2001;345(19):1359-1367. doi:10.1056/NEJMoa011300

5. Van den Berghe G, Wilmer A, Hermans G, et al. Intensive insulin therapy in the medical ICU. $N$ Engl J Med. 2006;354(5):449-461. doi:10.1056/NEJMoa052521 
6. Brunkhorst FM, Engel C, Bloos F, et al. Intensive insulin therapy and pentastarch resuscitation in severe sepsis. $N$ Engl J Med. 2008;358 (2):125-139. doi:10.1056/NEJMoa070716

7. Nice-Sugar Study Investigators. Intensive versus conventional glucose control in critically ill patients. $N$ Engl J Med. 2009;360 (13):1283-1297. doi:10.1056/NEJMoa0810625

8. Michalia M, Kompoti M, Koutsikou A, et al. Diabetes mellitus is an independent risk factor for ICU-acquired bloodstream infections. Intensive Care Med. 2009;35(3):448-454. doi:10.1007/s00134-0081288-0

9. Abdelhamid YA, Plummer MP, Finnis ME, et al. Long-term mortality of critically ill patients with diabetes who survive admission to the intensive care unit. Crit Care Resusc. 2017;19(4):303.

10. Christiansen CF, Johansen MB, Christensen S, O'Brien JM, Tønnesen E, Sørensen HT. Type 2 diabetes and 1-year mortality in intensive care unit patients. Eur J Clin Invest. 2013;43(3):238-247. doi:10.1111/eci.12036

11. Vincent JL, Preiser JC, Sprung CL, Moreno R, Sakr Y. Insulin-treated diabetes is not associated with increased mortality in critically ill patients. Crit Care. 2010;14(1):R12. doi:10.1186/cc8866

12. Graham BB, Keniston A, Gajic O, et al. Diabetes mellitus does not adversely affect outcomes from a critical illness. Crit Care Med. 2010;38(1):16-24. doi:10.1097/CCM.0b013e3181b9eaa5

13. Siegelaar SE, Hickmann M, Hoekstra BL, et al. The effect of diabetes on mortality in critically ill patients: a systematic review and meta-analysis. Crit Care. 2011;15(5):1-12. doi:10.1186/cc10440

14. Sechterberger MK, Bosman RJ, Oudemans-van Straaten HM, et al. The effect of diabetes mellitus on the association between measures of glycaemiccontrol and ICU mortality: a retrospective cohort study. Crit Care. 2013;17(2):R52. doi:10.1186/cc12572

15. Krinsley JS, Egi M, Kiss A, et al. Diabetic status and the relation of the three domains of glycemic control tomortality in critically ill patients: an international multicenter cohort study. Crit Care. 2013;17(2):R37. doi:10.1186/cc12547

16. Yatabe T, Inoue S, Sakaguchi M, Egi M. The optimal target for acute glycemic control in critically ill patients: a network meta-analysis. Intensive Care Med. 2017;43(1):16-28. doi:10.1007/s00134-0164558-2

17. Lanspa MJ, Hirshberg EL, Phillips GD, Holmen J, Stoddard G, Orme J. Moderate glucose control is associated with increased mortality compared with tight glucose control in critically ill patients without diabetes. Chest. 2013;143(5):1226-1234. doi:10.1378/ chest.12-2072

18. Ling Y, Li X, Gao X. Intensive versus conventional glucose control in critically ill patients: a meta-analysis of randomized controlled trials. Eur J Intern Med. 2012;23(6):564-574. doi:10.1016/j. ejim.2012.02.013

19. Krinsley JS, Preiser JC, Hirsch IB. Safety and efficacy of personalized glycemic control in critically ill patients: a 2-year before and after interventional trial. Endocr Pract. 2017;23(3):318-330. doi:10.4158/EP161532.OR

20. Johnson AE, Pollard TJ, Shen L, et al. MIMIC-III, a freely accessible critical care database. Sci Data. 2016;3:160035. doi:10.1038/ sdata.2016.35

21. Le Gall JR, Lemeshow S, Saulnier F. A new simplified acute physiology score (SAPS II) based on a European/North American multicenter study. JAMA. 1993;270(24):2957-2963. doi:10.1001/ jama.1993.03510240069035

22. Johnson A, Stone DJ, Celi LA, Pollard TJ. The MIMIC code repository: enabling reproducibility in critical care research. J Am Med Inform Assoc. 2017;25(1):32-39. doi:10.1093/jamia/ocx084
23. Lin S, Ge S, He W, Zeng M. Association of delayed time in the emergency department with the clinical outcomes for critically ill patients. $Q J$ Med. 2020. doi:10.1093/qjmed/hcaa192

24. Lin S, Ge S, He W, Zeng M. Association between body mass index and short-term clinical outcomes in critically ill patients with sepsis: a real-world study. Biomed Res Int. 2020;2020:5781913. doi:10.1155/ 2020/5781913

25. Rubin DB. Using propensity scores to help design observational studies: application to the tobacco litigation. Health Serv Outcomes Res Methodol. 2001;2:169-188. doi:10.1023/A:1020363010465

26. Robins JM, Hernán MA, Brumback B. Marginal structural models and causal inference in epidemiology. Epidemiology. 2000;11 (5):550-560. doi:10.1097/00001648-200009000-00011

27. Austin PC. Using the standardized difference to compare the prevalence of a binary variable between two groups in observational research. Commun Stat Simul Comput. 2009;38(6):1228-1234. doi:10.1080/03610910902859574

28. VanderWeele TJ, Ding P. Sensitivity analysis in observational research: introducing the E-value. Ann Intern Med. 2017;167 (4):268-274. doi:10.7326/M16-2607

29. Haneuse S, VanderWeele TJ, Arterburn D. Using the E-value to assess the potential effect of Unmeasured confounding in observational studies. JAMA. 2019;321(6):602-603. doi:10.1001/ jama.2018.21554

30. DiCiccio TJ, Efron B. Bootstrap confidence intervals. Stat Sci. 1996;189-212.

31. Ganeshan K, Chawla A. Metabolic regulation of immune responses. Annu Rev Immunol. 2014;32:609-634. doi:10.1146/annurev-immunol -032713-120236

32. Pearce EL, Pearce EJ. Metabolic pathways in immune cell activation and quiescence. Immunity. 2013;38(4):633-643. doi:10.1016/j. immuni.2013.04.005

33. Loftus RM, Finlay DK. Immunometabolism: cellular metabolism turns immune regulator. $J$ Biol Chem. 2016;291(1):1-10. doi:10.1074/jbc.R115.693903

34. Van Niekerk G, Davis T, Engelbrecht AM. Hyperglycaemia in critically ill patients: the immune system's sweet tooth. Crit Care. 2017;21(1):202. doi:10.1186/s13054-017-1775-1

35. van Niekerk G, Loos B, Nell T, Engelbrecht AM. Autophagy-A free meal in sickness-associated anorexia. Autophagy. 2016;12 (4):727-734. doi:10.1080/15548627.2016.1147672

36. Vanhorebeek I, Gunst J, Derde S, et al. Insufficient activation of autophagy allows cellular damage to accumulate in critically ill patients. J Clin Endocrinol Metab. 2011;96(4):E633-E645. doi:10.1210/jc.2010-2563

37. Pfeifer U. Inhibition by insulin of the physiological autophagic breakdown of cell organelles. Acta Biol Med Ger. 1977;36 (11-12):1691-1694.

38. Plummer MP, Bellomo R, Cousins CE, et al. Dysglycaemia in the critically ill and the interaction of chronic and acute glycaemia with mortality. Intensive Care Med. 2014;40(7):973-980. doi:10.1007/ s00134-014-3287-7

39. van Vught LA, Wiewel MA, Klein Klouwenberg PM, et al. Admission hyperglycemia in critically ill sepsis patients: association with outcome and host response. Crit Care Med. 2016;44 (7):1338-1346. doi:10.1097/CCM.0000000000001650

40. Carpenter DL, Gregg SR, Xu K, Buchman TG, Coopersmith CM. Prevalence and impact of unknown diabetes in the ICU. Crit Care Med. 2015;43(12):e541-e550. doi:10.1097/CCM.0000000000001353 


\section{Publish your work in this journal}

The Journal of Inflammation Research is an international, peerreviewed open-access journal that welcomes laboratory and clinical findings on the molecular basis, cell biology and pharmacology of inflammation including original research, reviews, symposium reports, hypothesis formation and commentaries on: acute/chronic inflammation; mediators of inflammation; cellular processes; molecular mechanisms; pharmacology and novel anti-inflammatory drugs; clinical conditions involving inflammation. The manuscript management system is completely online and includes a very quick and fair peerreview system. Visit http://www.dovepress.com/testimonials.php to read real quotes from published authors. 